Full length article

\title{
Health effects of caring for and about parents and spouses
}

\author{
Judith Bom ${ }^{\mathrm{a}, *}$, Pieter Bakx ${ }^{\mathrm{a}}$, Frederik Schut ${ }^{\mathrm{a}}$, Eddy van Doorslaer ${ }^{\mathrm{a}, \mathrm{b}, \mathrm{c}}$ \\ ${ }^{a}$ Erasmus School of Health Policy and Management, Erasmus University Rotterdam, Rotterdam, the Netherlands \\ ${ }^{\mathrm{b}}$ Erasmus School of Economics, Erasmus University Rotterdam, Rotterdam, the Netherlands \\ ${ }^{\mathrm{c}}$ Tinbergen Institute, Amsterdam, the Netherlands
}

\section{A R T I C L E I N F O}

\section{Keywords:}

Long-term care

Informal care

Caregiver effect

Family effect

JEL classification:

$\mathrm{J} 14$

I10

$\mathrm{J} 18$

\begin{abstract}
A B S T R A C T
Informal caregiving is a potentially attractive alternative to formal care but may entail health costs for the caregiver. We examine the mental and physical health impact of providing informal care and disentangle the caregiving effect - the effect of caring for someone in need - from the family effect - the effect of caring about someone in need. We account for the main sources of endogeneity in the caregiving decision using ArellanoBond difference GMM models. We use four waves (2010-2013) of panel data from the Dutch Study on Transitions in Employment, Ability and Motivation (STREAM).

We find that caregiving harms the mental health of caregivers; the effect is more prominent for spousal caregivers. On top of this, a negative health shock of a family member also has a direct negative effect on mental health, providing evidence of a family effect. Our findings thus highlight that the total effect of having a sick relative may be underestimated when the family effect is not adequately accounted for. As the caregiving effect differs substantially between various types of caregivers, policies to cushion these effects should specifically target those subgroups of caregivers that carry the largest burden of informal caregiving.
\end{abstract}

\section{Introduction}

In most Western countries, the demand for long-term care (LTC) is expected to keep rising in the decades to come. For instance, in the Netherlands the demand for LTC is projected to grow at an average annual rate of $1.6 \%$ between 2014 and 2030 (Eggink et al., 2016). Part of this growing demand is likely to be met by informal care, i.e. by unpaid care provided by relatives and friends. While the costs of informal caregiving are typically low for the recipient, they may be substantial for the caregiver and society. Various studies found that the stress and physical strain involved in informal caregiving risks hurting the health of caregivers (e.g. Pinquart and Sörensen, 2003). Many of these studies, however, used non-representative samples or focused on the provision of care for a specific disease (Hirst, 2004).

While the recent literature has moved towards estimating the impact of informal caregiving using larger, representative datasets, two main challenges of adequate empirical identification of these effects have emerged. A first challenge relates to the potential endogeneity between the decision to provide informal care and one's own health. Persons with lower health expectations might for example be more inclined to take up the caregiver role for their parents (Schulz, 1990). The other way around, a minimum level of health is required to be able to carry out caregiving tasks, which prevents individuals in very poor health from providing care. In addition, omitted variables may lead to bias when unobserved variables like personality affect both the propensity of providing care and the health of the caregiver.

A second challenge, which has received limited attention thus far, is dealing with the notion that two distinct effects may be present in situations of ill-health of a relative: the family effect and the caregiving effect. The family effect refers to the impact of caring about a person and, if living together, the consequences of taking over regular household chores. It is different from the caregiving effect, which is the effect of caring for a person in need. Irrespective of care provision, experiencing a health decline of a loved one can have a negative effect on one's own health or well-being (Amirkhanyan and Wolf, 2006; Bobinac et al., 2010).

It is important to make this distinction between the caregiving effect and the family effect, as addressing them adequately would require different government interventions. Respite care, for instance, could alleviate the caregiving effect, but offers no solution to the family effect of worrying about an ill family member. As the caregiving effect and the family effect often occur simultaneously, it is difficult to disentangle them. Yet, not controlling for the family effect might lead to overestimation of the caregiving effect.

This paper aims to improve understanding of the health effects experienced by informal caregivers by separately estimating both effects. In contrast to some earlier studies, we do not apply instrumental

\footnotetext{
* Corresponding author at: Erasmus University Rotterdam, Burgemeester Oudlaan 50, 3062 PA Rotterdam, the Netherlands.

E-mail address: bom@eshpm.eur.nl (J. Bom).
} 
variables to estimate the caregiving effect because the validity of the instruments used in previous work can be questioned, and strong and valid instruments are not readily available. Instead, we reduce endogeneity concerns by using Arellano-Bond difference GMM models to control for existing health differences in a first-differences regression.

While most papers focus on either parental or spousal caregiving, we separately estimate the caregiving effect and the family effect for various groups of caregivers. There may be various reasons why the impact of caregiving differs between these care types. As spousal caregivers tend to be older, they often have fewer physical and psychological resources to deal with stress related to caregiving (Pinquart and Sörensen, 2003). Furthermore, differences in the level of care provision can be large drivers of differences in stress between spousal and parental caregivers (Pinquart and Sorensen, 2011).

\section{Earlier work on health effects of informal caregiving}

A number of studies have attempted to address endogeneity problems when evaluating the health effects of informal caregiving by using instrumental variables (IVs), fixed effects (FE) methods or statistical matching (see Table A1 in the appendix for an overview). The first group of studies used IVs to estimate the impact of informal care provision (Coe and Van Houtven, 2009; Do et al., 2015; Heger, 2016) and found significant negative effects of informal caregiving on the caregiver's health. The IVs employed in these studies all relate to the health of one's parents. The risk of these instruments lies in their potential violation of the exclusion restriction; when a family effect is present, a health shock of a family member is correlated directly to the caregiver's health. Using health of a family member as IV for informal caregiving could therefore overestimate the effect of caregiving on health by attributing the entire difference in health between individuals with and without ill family members to caregiving.

The second group of studies, most closely linked to the set-up of the current paper, aims to estimate a causal impact by controlling for or matching on a large set of covariates. These studies rely on the assumption that they are able to capture all covariates that affect the caregiving decision to make the conditional independence assumption hold. While this is a strong assumption, it might be preferable considering worries related to the validity of IVs. Van den Berg et al. (2014) used FE models on an Australian dataset and found significant negative effects of caregiving on subjective wellbeing. Using FE models they controlled for time constant heterogeneity, however they did not consider selection into caregiving based on time-variant elements such as previous health. The studies making use of matching (Brenna and Di Novi, 2016; de Zwart et al., 2017; Schmitz and Westphal, 2015), addressed endogeneity of caregiving by statistically matching caregivers and non-caregivers on observable characteristics. By matching on pre-treatment variables, these papers make it credible that treatment is random conditional on controls and hence that an average treatment effect on the treated can be identified. All three papers found negative effects of caregiving on mental health.

Thus far, two studies specifically considered the family effect. Do et al. (2015) aimed to avoid picking up the family effect by only focusing on (i) physical health effects and (ii) females providing care to their parents-in-law. They found negative health effects of providing informal care, but might face difficulties in isolating the family effect from the caregiving effect. For example, as mental and physical health could affect each other, stress related to the family effect may induce physical health problems. Heger (2016) estimated the family effect by including an indicator of poor health of a parent in the model and found a negative effect of poor health of family members on the health of the potential caregiver.

\section{Methods}

To deal with the potential endogeneity between caregiving and own health, we start from the economic intuition behind the caregiving decision as presented by De Zwart et al. (2017). According to their model, a set of elements affect the caregiving decision. The first one relates to personal ability, both reflected in wage and health. Persons with a higher ability might, for example, prefer paid work to providing informal care. Second, availability of other types of informal and formal care might affect the caregiving decision. Household income and size could for example reflect someone's possibilities to purchase formal care or to transfer caregiving duties to family members. Lastly, non-monetary factors such as cultural factors might affect the caregiving decision.

We account for these factors that shape the caregiving decision in three ways. First, we use a first-difference model to control for timeinvariant personal characteristics, like personality traits and education.

Second, we deal with differential selection into caregiving by health status by conditioning on the lagged health status. Controlling for lagged health not only deals with reverse causality but also helps to mitigate the issue of unobserved characteristics (cf. Lechner, 2009). Variations in time-variant factors that are potentially affecting current health status of the respondents occurring in $t-1$ and earlier are likely to have also affected lagged health and thus need not to be controlled for anymore. Hence, we assume that no event affected both the propensity to care and one's own health in the past year.

To include a lagged variable while controlling for time-invariant unobservables, we use the Arellano-Bond (1991) (A-B) estimation technique. Including pre-treatment health status in a regular FE or first-difference model is not possible as the lagged dependent variables correlate with the fixed effects in the error term and would give rise to dynamic panel bias. This bias could affect our estimates of the lagged dependent variable, as well as the coefficients of our other independent variables, especially when the dataset contains few waves but many observations (Nickell, 1981). In the A-B first-differences model, the lagged difference in health status $H\left(\Delta H_{i t-1}\right)$ is instrumented by deeper lags of health (starting with health two waves earlier: $H_{i t-2}$ ). We can use $H_{i t-2}$ as an instrument for $\left(\Delta H_{i t-1}\right)$ because $H_{i t-2}$ is correlated with $\left(\Delta H_{i t-1}\right)$ but not with $\Delta \varepsilon_{i t}$ as long as the error terms are not serially correlated. Following Arellano and Bond (1991), we do not only use the second lag of health, but all available deeper lags of health as instruments. As we have four waves of data, we can include the second and third lag.

Third, we control for remaining observed time-varying factors related to the caregiving decision and own health by including covariates (such as income and marital status) into our models. The main difference between this study and prior studies is that we include measures to capture the family effect in the model. Based on the existing literature, we cannot conceive other important, time-varying factors affecting own health and the caregiving decision.

The resulting dynamic panel data model is estimated using a difference Generalized Method of Moments (GMM) regression. ${ }^{1}$ The model is specified as follows:

$\Delta H_{i t}=\beta_{1} \Delta H_{i, t-1}+\beta_{2} \Delta I C_{i t}+\beta_{3} \Delta H F_{i t}+\beta_{4} \Delta X_{i t}+\Delta \varepsilon_{i t}$

The change in health $\Delta H_{i t}$ is dependent on the change in one's health status observed one year before, $\Delta H_{i, t-1}$; on $\Delta I C_{i t}$, which indicates the change of the informal care provision status; on $\Delta H F_{i t}$, which refers to a change in the health state of the individual's partner or close family member, ${ }^{2}$ as well as a vector of changes in individual time-varying characteristics, $\Delta X_{i t}$. All time-invariant individual characteristics are factored out by differencing. Our main parameters of interest are $\beta_{2}$, indicating the caregiving effect, and $\beta_{3}$, indicating the family effect.

\footnotetext{
${ }^{1}$ We present robust twostep estimates using the Stata command xtabond2 (Roodman, 2006)

${ }^{2}$ The caregiving effect and the family effect might reinforce each other, for example, when care provision becomes more challenging due to severe illness of the care recipient. Adding an interaction term to the model, we indeed observe a positive interaction between the two effects. We do not include this interaction term in the models presented in this paper, as the approach is highly data demanding.
} 
Data

We use the Dutch Study on Transitions in Employment, Ability and Motivation (STREAM) panel survey, which includes four annual waves of data ranging from 2010 to 2013. It collects extensive information on determinants of transitions into and out of employment and of work productivity among persons aged $45-64$ years. This is also the age group providing most informal care in the Netherlands (Gezondheidsmonitor, 2016). The STREAM sample is stratified at baseline on age and work status and is drawn from an existing internet panel (Ybema et al., 2014). In the first wave, 15,118 persons responded to the survey. In later waves, this original sample was invited to participate again without replacement. Attrition is fairly low: in total almost two-thirds (64\%) of the sample responded to all four surveys. The panel data are linked at the individual level to administrative data for all registered inhabitants in the Netherlands obtained via Statistics Netherlands. ${ }^{3}$

Sample

From the 15,118 first wave respondents, we select a subsample of individuals who could potentially provide informal care to their parent or partner. We do so by only including respondents who have a living parent or partner at baseline. As the difference GMM regression requires at least three waves of data, we solely include individuals who responded at least three times to the survey. Table A2 in the appendix provides an overview of the inclusion criteria. Our sample at baseline consists of 4,400 males and 3,528 females; across all waves we have 17,055 male and 13,693 female observations. ${ }^{4}$

\section{Health measurement}

The panel data enable us to use four complementary, validated selfreported health outcomes. The first two measures are derived from the SF-12 health survey, which contains questions regarding health during the past four weeks. From this survey, we derive two subscales: the Physical Component Summary Scale (PCS) and the Mental Component Summary Scale (MCS). ${ }^{5}$ Both scales range from 0 to 100, a higher score equals a better health status (Ware et al., 1995).

In addition to these general mental and physical health scores, we use two measures that capture specific aspects of health that are particularly likely to be affected by caregiving; fatigue and depression. Informal caregiving often leads to caregiver fatigue because caregivers may prioritize the patient's needs over their own (Schulz et al., 1990). Additionally, the stress involved in caregiving (Pinquart and Sörensen, 2003), as well as the stress caused by illness of family members (Amirkhanyan and Wolf, 2006), can lead to an increase in depressive symptoms. Fatigue is measured using the SF-36 vitality subscale $(0-100)$ based on responses to four items, ${ }^{6}$ where a higher score relates to lower fatigue/higher vitality (Ware et al., 1993). ${ }^{7}$ To measure depression, we use the CES-D-10 scale (0-30). A higher score relates to increased presence of depressive symptoms (Andresen et al., 1994).

\footnotetext{
${ }^{3}$ We use non-public microdata which, when adhering to various conditions, can be accessed via a secured remote access connection.

${ }^{4}$ We consider this sample a random subsample, no large discrepancies in observable characteristics between the subsample and total sample were detected.

${ }^{5}$ The scales consists of the following sub-scales: Physical functioning (2 questions), Role-Physical (2 questions), Bodily Pain and General Health, Vitality, Social Functioning, Role-Emotional (2 questions) and Mental Health (2 questions).

${ }^{6}$ The past four weeks: (1) Did you feel full of life? (2) Did you have a lot of energy? (3) Did you feel worn out? (4) Did you feel tired?

${ }^{7}$ Although the vitality subscale was developed as part of a broader health measure, the subscale is used in isolation in various patient populations (e.g. Hewlett, Dures, \& Almeida, 2011).
}

Following scoring instructions (Andresen et al., 1994; Ware et al., 1995; Ware et al., 1993), health scores were reported as missing in case the respondent failed to answer any (MCS \& PCS), > 1 question (CES-D-10) or $>2$ questions (vitality scale).

\section{Measurement of informal caregiving}

The main variable of interest is a binary variable indicating whether someone provided informal care (IC) in the past year. Respondents were asked: 'Did you in the past 12 months spend part of your time on any of the following activities?' When they answer 'Giving informal care' affirmatively, they are considered informal caregivers. ${ }^{8}$ In the last two waves of the survey, respondents were also asked to indicate to whom they provided care. To analyze differences in the type of care provided, we distinguish between spousal, parental and other types of caregiving in subgroup analyses. Based on the 2012 and 2013 observations, we impute the type of care in the first two waves assuming that the care recipient (parent or spouse) remains the same throughout the years. ${ }^{9}$ In Table A3 in the appendix an overview of the number of informal caregivers is given, specified by care recipient. As our sample is limited to respondents aged $45-65$ we do not capture the entire caregiving population, especially spousal caregivers tend to be older and hence underrepresented in our data. Our results might therefore underestimate the average health effect for the full population of caregivers, as older caregivers might be more prone to the negative health effects of caregiving (Pinquart and Sörensen, 2003).

\section{Covariates}

As explained in the methods section, we take first-differences and control for lagged health. We furthermore estimate the family effect by including a variable indicating whether the respondent indicated that a spouse or close family member has become severely ill within the past year. Furthermore, we include the following individual-level covariates: age, age-squared, self-reported financial difficulties, ${ }^{10}$ percentile group of standardized household income, marital status, having children living at home, employment status, ${ }^{11}$ and whether or not the father or mother is alive. Finally, we include wave dummies to capture time trends affecting all respondents, including for instance any trends in formal LTC use. ${ }^{12}$

\section{Results}

\section{Descriptive statistics}

Table 1 presents descriptive statistics for our sample at baseline, stratified by respondent caregiver status. Caregivers are more often

\footnotetext{
${ }^{8}$ Informal care (in Dutch: Mantelzorg) refers to providing non-professional care for a person in need in your own close environment, it does not include looking after healthy family members.

${ }^{9}$ This assumption seems credible, between 2012 and 2013 the care recipient changed in only $4 \%$ (spouses) and $7 \%$ (parents) of the cases.

${ }^{10}$ This variable equals 1 when the respondent indicated that their household is currently very short or a bit short on money.

${ }^{11}$ Next to health effects, informal care might also affect someone's work situation. Including income and employment as control variables might therefore bias results when these variable act as dependent variables ('bad controls') in the model (Angrist \& Pischke, 2008). However, Rellstab et al. (2018) show that, as the Dutch LTC system is generous and comprehensive, there are no direct employment and income effects and hence we include these control variables in the model. When testing this decision empirically, we do not observe large differences in our main estimations dependent on inclusion of these variables.

${ }^{12}$ There are no differences across regions or between households in formal care availability that we need to account for. In general, co-payments are low and income-related and there are virtually no waiting lists for formal care use (Mot, 2010).
} 
Table 1

Descriptive statistics of baseline sample.

\begin{tabular}{|c|c|c|c|c|c|}
\hline & \multicolumn{2}{|c|}{$\begin{array}{l}\text { Never informal } \\
\text { caregiver }\end{array}$} & \multicolumn{2}{|c|}{$\begin{array}{l}\text { Ever informal } \\
\text { caregiver }\end{array}$} & \multirow[b]{3}{*}{$3-1$} \\
\hline & Mean & SD & Mean & SD & \\
\hline & 1 & 2 & 3 & 4 & \\
\hline \multicolumn{6}{|l|}{ Health outcomes } \\
\hline SF-12 physical component scale & 49.27 & 9.75 & 48.82 & 9.98 & * \\
\hline SF-12 mental component scale & 52.64 & 8.26 & 51.24 & 9.46 & $* * *$ \\
\hline SF-36 vitality scale & 66.31 & 19.11 & 63.85 & 19.79 & $* * *$ \\
\hline CES-D-10 depression index & 5.03 & 4.83 & 5.70 & 5.30 & $* * *$ \\
\hline \multicolumn{6}{|l|}{ Health family } \\
\hline Severe illness of spouse/family member & 0.14 & 0.34 & 0.27 & 0.45 & $* * *$ \\
\hline Severe illness of spouse & 0.02 & 0.15 & 0.07 & 0.25 & $* * *$ \\
\hline Severe illness of close family & 0.12 & 0.32 & 0.22 & 0.41 & $* * *$ \\
\hline \multicolumn{6}{|l|}{ Personal characteristics } \\
\hline Age & 53.74 & 5.52 & 53.94 & 5.20 & \\
\hline Age Squared & 2918.66 & 596.09 & 2936.92 & 562.26 & \\
\hline Gender & 0.35 & 0.48 & 0.57 & 0.49 & $* * *$ \\
\hline Married/registered partnership & 0.87 & 0.34 & 0.83 & 0.38 & $* * *$ \\
\hline Children living at home & 0.47 & 0.50 & 0.44 & 0.50 & $* * *$ \\
\hline Employed & 0.89 & 0.32 & 0.85 & 0.35 & $* * *$ \\
\hline Perc. group household income & 68.20 & 22.71 & 67.92 & 23.33 & \\
\hline Financial difficulties & 0.19 & 0.39 & 0.20 & 0.40 & * \\
\hline Father alive & 0.53 & 0.50 & 0.66 & 0.47 & $* * *$ \\
\hline Mother alive & 0.31 & 0.46 & 0.35 & 0.48 & $* * *$ \\
\hline \multicolumn{6}{|l|}{ Informal caregiving } \\
\hline Average care duration (\# waves) & & & 2.25 & 1.25 & $* * *$ \\
\hline Number of observations in $T_{1}$ & 4,654 & & 3,273 & & \\
\hline Total number of observations & 17,981 & & 12,758 & & \\
\hline
\end{tabular}

SF-12 PCS and MCS and SF-36 Vitality range from 0 to 100 (lowest - highest level of health). CES-D-10 ranges from 0 to 30 . A score $\geq 10$ is considered a sign of depression. ${ }^{* * * *} p<0.01 ;{ }^{* * *} p<0.05 ;{ }^{*} p<0.1$ indicate differences between never and ever informal care sample.

females, and have a lower health status at baseline. As expected, informal caregivers more often have ill family members. Table A4 in the appendix presents the descriptive statistics for the sample stratified by gender.

\section{Health effects}

The estimation results of the A-B models presented in Table 2 suggest that informal caregiving only has a negative effect on mental health as measured by the MCS. The effect is small compared to the mean MCS score (only about 1\%). We also observe significant family effects on mental health: a severe illness occurring to a family member leads to a significant decrease in the mental health score of about the same size as the caregiving effect and to a significant increase in depressed feelings. ${ }^{13}$ Only changes in a few other covariates (i.e. having financial difficulties, being employed, and mother alive) are associated with health changes.

The family effect is important in itself, but also because omitting it from a regression may lead to an upward bias of the estimate of the caregiving effect. To examine the importance of not considering the family effect on the magnitude of the caregiving effect, we reran our analysis while excluding the family effect. The estimated coefficients of the health effect of informal caregiving in both models are presented in Table 3. It shows that ignoring the family effect in these models would, compared to our main model, yield a slightly higher estimate for the caregiving effect for mental health scores, though the difference is not significant. We do not find an effect for the physical health score.

\footnotetext{
${ }^{13}$ In additional regressions we verified whether the family effect differed when including hours of care instead of a dummy for informal care. This turned out not to be the case (results available upon request).
}

The family effect and the caregiving effect differ by gender (see: Table A5 in the appendix); both the caregiving effect and the family effect only affect the mental health of females. ${ }^{14}$ Males, by contrast, experience a physical health decline in response to informal caregiving. This difference does not seem to be driven by hours spent caring, since male and female caregivers in the sample devote roughly the same amount of time to care.

Our A-B models rely on deeper lags of health to instrument the lagged first-difference in health. The first stage results show the relevance of these instruments (Table A6): the excluded lagged levels of health are strongly correlated with the lagged difference in health. This is confirmed by the Kleibergen-Paap Wald $r k F$-statistics for the excluded instruments, indicating that the instruments are strong. The Hansen (1982) J-test statistics for overidentifying restrictions provide an indication of the validity of our instruments: for all models, we cannot reject the null-hypothesis that all instruments are valid. ${ }^{15}$

\section{Heterogeneous effects: subsample analyses}

In order to assess whether the caregiving effect and the family effect differ for various types of caregiving, we carry out several subsample analyses. These subgroup analyses are of interest in themselves, but also facilitate an easier comparison with prior studies which often focused on subgroups only. First, we analyze whether the provision of more informal care also leads to larger health damage. There indeed appears to be a dose-response relationship: for individuals that start providing at least eight hours of care per week ${ }^{16}$ ( $31 \%$ of the caregivers provide at least this amount of care), the impact of informal care on mental health and vitality is considerably larger than for the group providing less than eight hours of care per week (Table 4).

The caregiving effect is larger when caring for a spouse instead of someone else (Table 5). Spousal caregiving especially affects vitality and depression scores. These effects are substantial; caregiving relates to a change of for example more than $10 \%$ of the average CES-D-10 score. We also observe a difference in terms of the family effect; a severe illness of a spouse has a negative effect on mental health and vitality scores and increases depression scores, but these effects are absent when a parent or other close family member falls ill.

For all subgroup analyses, the results stratified by gender can be found in the appendix. Tables A7 and A8 show that all effects (except for the physical health effect) are larger for females and often significantly different by gender. ${ }^{17}$

\footnotetext{
${ }^{14}$ The differences in the caregiving effects by gender are significant for PCS, MCS and CESD at the $0.05,0.10$ and 0.05 level, respectively.

${ }^{15}$ The difference GMM model furthermore relies on the assumption of no serial correlation among the errors, which can be assessed using the test proposed by Arellano and Bond (1991). This test focuses on finding autocorrelation among the differenced error terms. We cannot test for second order autocorrelation, as it requires five waves of data. In the absence of any formal test for this assumption, we rely on Coe and Van Houtven (2009) and Roy and Schurer (2013) who did not find any second order serial correlation of the residuals for mental health in a similar model. We also estimated our model using a deeper lag of health $\left(\mathrm{H}_{\mathrm{it}-3}\right)$ instead of both $\mathrm{H}_{\mathrm{it}-3}$ and $\mathrm{H}_{\mathrm{it}-2}$, which would solve the problem in case any second order correlation was present. Use of this deeper lag of health hardly affected our estimates, supporting the validity of our assumption.

${ }^{16}$ We use the threshold of $\geq 8 \mathrm{~h}$ following the definition of informal care of Statistics Netherlands (2016)

${ }^{17}$ The caregiving effect of 1-7 hours of care differs by gender for PCS, MCS and CESD at the 0.05, 0.10 and 0.05 level, for intensive caregiving this difference is present for PCS and vitality at the 0.05 and 0.10 level. The difference in the parental caregiving effect is significantly different by gender for vitality and depression at the 0.01 and 0.10 level. The difference in the spousal caregiving effect by gender is significantly different for PCS, MCS and depression at the $0.05,0.05$ and 0.10 level.
} 
Table 2

Arellano-Bond difference GMM regressions.

\begin{tabular}{|c|c|c|c|c|}
\hline \multirow[t]{2}{*}{ A-B } & \multicolumn{4}{|l|}{ Both genders } \\
\hline & SF-12 PCS & SF-12 MCS & SF-36 vitality & CES-D-10 depression \\
\hline Informal care & $-0.07(0.19)$ & $-0.45^{k *}(0.22)$ & $-0.49(0.35)$ & $0.14(0.10)$ \\
\hline Severe illness spouse/family & $0.14(0.15)$ & $-0.43^{k+* x+1}(0.17)$ & $-0.29(0.27)$ & $0.16^{\text {**x }}(0.08)$ \\
\hline Lagged health & $0.10^{\text {t.kxkxkx}}(0.02)$ & $0.11^{* * * *}(0.02)$ & $0.09^{\text {*k*k*k}}(0.02)$ & $0.09^{k * *}(0.02)$ \\
\hline Employed & $0.46(0.29)$ & $-0.23(0.31)$ & $-1.74^{* * * *}(0.54)$ & $-0.01(0.16)$ \\
\hline Financial difficulties & $-0.22(0.21)$ & $-0.18(0.25)$ & $-1.14^{* * * k}(0.40)$ & $0.32^{* * * * x}(0.12)$ \\
\hline Perc. group household income & $-0.01(0.01)$ & $0.01^{*}(0.00)$ & $0.01(0.01)$ & $-0.00(0.00)$ \\
\hline Age & $0.43(0.53)$ & $-0.68(0.54)$ & $-0.20(0.97)$ & $0.29(0.27)$ \\
\hline Age Squared/100 & $-0.47(0.48)$ & $0.61(0.48)$ & $0.08(0.86)$ & $-0.23(0.24)$ \\
\hline Married/Registered partnership & $-0.58(0.54)$ & $1.18(0.77)$ & $1.26(1.11)$ & $-0.65^{*}(0.36)$ \\
\hline Children living at home & $-0.07(0.30)$ & $-0.30(0.33)$ & $-0.48(0.56)$ & $0.14(0.16)$ \\
\hline Mother Alive & $0.10(0.39)$ & $-0.98^{\text {*** }}(0.43)$ & $-0.84(0.70)$ & $0.06(0.20)$ \\
\hline Father Alive & $0.54(0.40)$ & $-0.21(0.51)$ & $-0.22(0.74)$ & $0.21(0.22)$ \\
\hline Hansen J-test (p-value) & $0.50(0.78)$ & $0.96(0.61)$ & $3.2(0.21)$ & $2.86(0.24)$ \\
\hline Number of instruments & 3 & 3 & 3 & 3 \\
\hline $\mathrm{N}$ & 13,626 & 13,626 & 14,824 & 14,822 \\
\hline Unique individuals & 7,430 & 7,430 & 7,892 & 7,893 \\
\hline
\end{tabular}

Robust standard errors are in parentheses. All regressions include wave dummies. ${ }^{* * * *} \mathrm{p}<0.01$; ${ }^{* *} \mathrm{p}<0.05 ;$; $\mathrm{p}<0.1$. Depending on the model that is estimated, lagged health refers to the lag of the corresponding dependent variable.

Table 3

Coefficients caregiving effect in model with or without family effect.

\begin{tabular}{|c|c|c|c|c|}
\hline \multirow[t]{2}{*}{ A-B } & \multicolumn{4}{|l|}{ Both genders } \\
\hline & SF-12 PCS & SF-12 MCS & SF-36 vitality & CES-D-10 depression \\
\hline Informal care (in model with family effect) & $-0.07(0.19)$ & $-0.45^{* *}(0.22)$ & $-0.49(0.35)$ & $0.13(0.10)$ \\
\hline Informal care (in model without family effect) & $-0.05(0.19)$ & $-0.49^{k+k}(0.22)$ & $-0.52(0.34)$ & $0.15(0.10)$ \\
\hline
\end{tabular}

Table 4

A-B estimates for subgroups stratified by caregiving intensity.

\begin{tabular}{|c|c|c|c|c|}
\hline A-B intensive care & \multicolumn{4}{|l|}{ Both genders } \\
\hline $1-7 \mathrm{~h}$ of informal care & $-0.09(0.20)$ & $-0.32(0.23)$ & $-0.26(0.37)$ & $0.13(0.11)$ \\
\hline Illness family member & $0.14(0.15)$ & $-0.42^{* *}(0.17)$ & $-0.27(0.27)$ & $0.16^{\text {**x }}(0.08)$ \\
\hline Hansen J-test & $0.5(0.78)$ & $0.98(0.61)$ & $3.2(0.20)$ & $2.85(0.24)$ \\
\hline Number of instruments & 3 & 3 & 3 & 3 \\
\hline
\end{tabular}

Robust standard errors are in parentheses. Included controls: lagged health, age, age ${ }^{2}$, financial difficulties, married, children at home, employed, standardized household income, mother alive, father alive, wave dummies. ${ }^{* * * *} \mathrm{p}<0.01$; ${ }^{* * *} \mathrm{p}<0.05$; ${ }^{*} \mathrm{p}<0.1$.

Table 5

A-B estimates for informal care to various types of care receivers.

\begin{tabular}{|c|c|c|c|c|}
\hline A-B different caregivers & \multicolumn{4}{|l|}{ Both genders } \\
\hline Informal care to spouse & $-0.82(0.61)$ & $-1.05(0.73)$ & $-1.85^{*}(1.04)$ & $0.71^{* * * x}(0.28)$ \\
\hline Informal care to other person & $0.01(0.28)$ & $-0.29(0.29)$ & $-0.56(0.49)$ & $0.08(0.13)$ \\
\hline Spouse severely ill & $-0.18(0.16)$ & $-1.04^{* * 1 *}(0.43)$ & $-1.51^{\text {w.t. }}(0.65)$ & $0.45^{* * *}(0.19)$ \\
\hline Close family member severely ill & $0.18(0.16)$ & $-0.22(0.18)$ & $0.00(0.29)$ & $0.10(0.08)$ \\
\hline $\mathrm{N}$ & 13,626 & 13,626 & 14,824 & 14,822 \\
\hline Unique individuals & 7,430 & 7,430 & 7,892 & 7,893 \\
\hline
\end{tabular}

Robust standard errors are in parentheses. Included controls: Lagged health, age, age ${ }^{2}$, financial difficulties, married, children at home, employed, financial difficulties, standardized household income, wave dummies. ${ }^{* * * *} \mathrm{p}<0.01 ;{ }^{* * *} \mathrm{p}<0.05 ;$ " $\mathrm{p}<0.1$. 


\section{Robustness analyses}

Results for several tests of robustness of our model estimates are presented in the appendix. To test whether the GMM model is able to overcome the dynamic panel bias, we first compare the A-B output with OLS and FE estimation results (Tables A9 and A10). As OLS (not controlling for individual fixed effects) and FE (suffering from dynamic panel bias), lead to biases in different directions, the estimates of both models represent upper and lower bounds for our autoregressive coefficient (Bond, 2002). Our A-B estimate of lagged health is indeed bounded by the OLS and FE estimates. The estimated caregiving effect and family effect in both models do not differ substantially from the A-B estimates.

Second, in all our models, we rely on self-reported information regarding health shocks of family members. This variable could be prone to justification bias: caregivers may justify their decision to provide care (and possibly their withdrawal from the labor market) by overstating the need of their family member (Bound, 1991). To rule this out, we rerun all models using a variable indicating the occurrence of a negative health shock of a family member (i.e. parent or spouse) as obtained from administrative data. For this test, we use a variable indicating whether a parent or spouse has become eligible for formal LTC in the current year because this indicates a substantial health decline that causes functional limitations and thus a need for both professional and informal help. The estimated coefficients for the family effect do not differ much between both indicators, except for the coefficient for the MCS which becomes insignificant and positive (Table A11). We use severe illness instead of LTC eligibility in the main analyses, as this variable covers a broader set of health problems.

Furthermore, our model might overestimate the caregiving effect when our indicator of the family effect does not capture all family health shocks. To test this, we include a selection of variables regarding the health of spouses and parents from administrative data. These administrative data include annual outpatient prescription drug use at the ATC 3 level, eligibility for publicly funded formal home care and nursing home care, and various types of health insurance spending such as GP care, hospital care and nursing care. As these data contain a very large number of potential indicators that would reduce any omitted variable bias, we use LASSO regression to select the most relevant variables (Belloni et al., 2012). The caregiving effect on mental health persists after adding these additional health variables, which suggests that the effect in the main analysis is robust to more extensive control for the family effect (Table A12). As including multiple measures of family health shocks means that the family effect is no longer easy to interpret, we rely on the health shock indicator in our main models.

Finally, we test the robustness of our results using a different methodology. Instead of the A-B method, we use a bias-correction estimation method to correct for the dynamic panel bias. For this test we make use of the Stata command $x t l s d v c$ (Bruno, 2005). The estimated caregiving and family effect closely match our initial results (Table A13). We prefer to rely on difference-GMM methods in our main models as it is better suited towards models where the number of observations is large (Bruno, 2005).

\section{Discussion and conclusion}

Illness and frailty may have health consequences for individuals who care for and care about spouses and parents in bad health, i.e. the caregiving effect and the family effect. Most of the literature to date did not distinguish between these two. Using a Dutch panel survey of respondents aged 45-65, we find evidence for both effects, particularly on mental health. Our estimates of the caregiving effect on mental health are smaller than those of previous studies such as De Zwart et al. (2017) and Schmitz and Westphal (2015). For example Schmitz and Westphal (2015) reported an impact of caregiving on mental health of -2 on the MCS for female caregivers, in contrast to -0.8 in this study.

Our findings contribute to the literature on informal caregiving in a number of ways. First, they highlight the importance of estimating the family effect separately: the onset of an illness of a family member has spillover effects to both caregiving and non-caregiving family members that can add to the burden of providing informal care. Thus, considering the family effect is important, even though in this study controlling for the family effect does not have implications for the estimated caregiving effect itself. Additionally, ignoring the family effect and using health of a family member as an instrument for informal caregiving is problematic because the direct negative effect of the health of a family member on the caregiver's health means that the exclusion restriction of the instrument is likely to be violated.

Second, we conducted interesting subgroup analyses. These indicate that female caregivers experience larger caregiving effects on mental health than male caregivers. Explanations could be that females are more often the primary caregiver and more likely to experience social pressure to become a caregiver (Pinquart \& Sörensen, 2003). The caregiving effect is also especially large for spousal caregivers. This finding may derive from a different intensity of caregiving; descriptive statistics show that spousal caregivers often provide more hours of informal care than other types of caregivers.

The findings of significant negative caregiving effects and family effects on mental health indicate that policymakers who seek to mitigate the negative spillovers from illness of an elderly person should focus on relieving the burden of caregiving activities but should not neglect the other family members. Furthermore, the findings show that the impact of caregiving is not the same for all subgroups of caregivers. Especially female and spousal caregivers experience large negative mental health effects of caregiving. Policymakers could specifically aim to support these groups of caregivers with targeted interventions.

\section{Acknowledgements}

The authors gratefully acknowledge comments on earlier versions of this article by Johan Bonekamp, Rudy Douven, Agnès Gramain, Sara Rellstab and Marianne Tenand. We also thank participants of various seminars and conferences for useful comments and discussion, and TNO and Statistics Netherlands for providing access to survey and administrative data. This study received financial support from the Network for Studies on Pensions, Aging and Retirement. Grant: Optimal saving and insurance for old age: The role of public-long term care insurance.

\section{Declaration of interest}

The authors declare no conflicts of interest. 


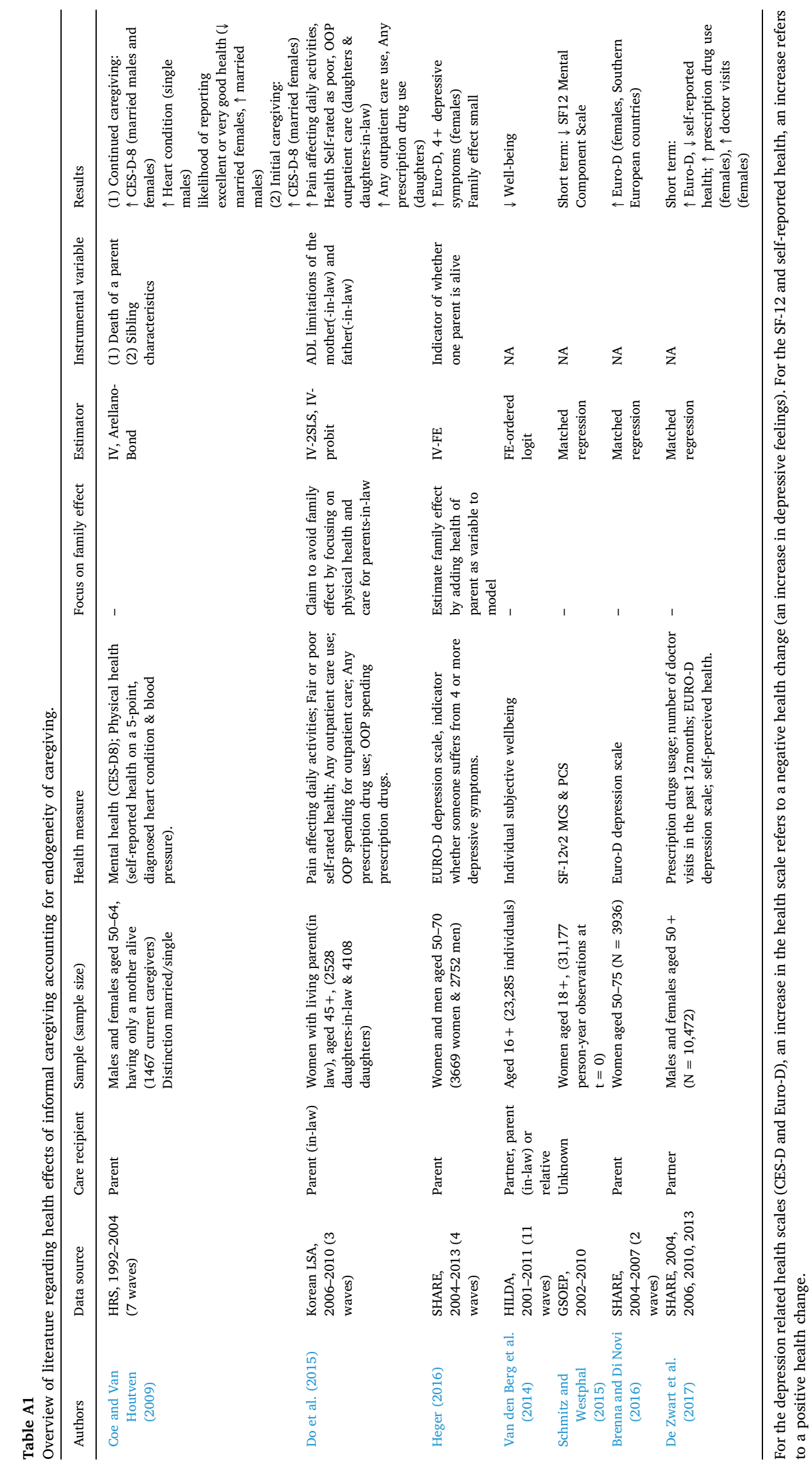


Table A2

Sample size and sample selection criteria.

\begin{tabular}{ll}
\hline Inclusion criteria & $\begin{array}{l}\text { Overall sample (\% } \\
\text { of total) }\end{array}$ \\
\hline Total respondents at $\mathrm{T}_{1}(2010)$ & 15,118 \\
Agreement to be linked to administrative data & $13,672(90.4)$ \\
Identified in administrative data & $13,398(88.6)$ \\
Did not submit survey twice in same wave & $13,218(87.4)$ \\
Having at least one parent alive and/or having a spouse & $10,855(71.8)$ \\
$\quad$ Fully completed $\geq 3$ surveys & $7,928(52.6)$ \\
Total number of respondents included $T_{1}$ & 7,928 \\
\hline
\end{tabular}

Table A3

Number of informal caregivers, specified by care recipient.

\begin{tabular}{|c|c|c|c|c|c|c|c|c|}
\hline & \multicolumn{4}{|l|}{ Males } & \multicolumn{4}{|c|}{ Females } \\
\hline & 2010 & 2011 & 2012 & 2013 & 2010 & 2011 & 2012 & 2013 \\
\hline Total informal caregivers (includes other care recipients) & 653 & 699 & 697 & 867 & 1156 & 1202 & 1267 & 1168 \\
\hline Started providing informal care & & 277 & 320 & 322 & & 310 & 337 & 304 \\
\hline Stopped providing informal care & & 231 & 228 & 168 & & 263 & 270 & 253 \\
\hline Average number of hours of informal care per week & 8.24 & 8.19 & 8.48 & 8.13 & 9.01 & 8.47 & 8.53 & 7.97 \\
\hline Providing informal care to close family member (parent) & $238^{\mathrm{a}}$ & $292^{\mathrm{a}}$ & 394 & 433 & $625^{\mathrm{a}}$ & $686^{\mathrm{a}}$ & 804 & 732 \\
\hline Providing informal care to spouse & $94^{\mathrm{a}}$ & $112^{\mathrm{a}}$ & 140 & 174 & $114^{\mathrm{a}}$ & $128^{\mathrm{a}}$ & 134 & 131 \\
\hline
\end{tabular}

a: Imputed based on care recipient in 2012-2013.

Table A4

Descriptive statistics of sample at baseline.

\begin{tabular}{|c|c|c|c|c|c|c|c|c|c|c|}
\hline \multirow{2}{*}{ Health outcomes } & \multicolumn{5}{|l|}{ Male } & \multicolumn{5}{|l|}{ Female } \\
\hline & \multicolumn{2}{|c|}{ Never Informal caregiver } & \multicolumn{2}{|c|}{ Ever Informal caregiver } & & \multicolumn{2}{|c|}{ Never Informal caregiver } & \multicolumn{2}{|c|}{ Ever Informal caregiver } & \\
\hline SF-12 physical component scale & 50.35 & 8.39 & 50.35 & 8.52 & & 47.28 & 11.59 & 47.67 & 10.81 & \\
\hline SF-12 mental component scale & 53.15 & 7.69 & 51.72 & 9.26 & $* * *$ & 51.70 & 9.15 & 50.88 & 9.59 & ** \\
\hline SF-36 vitality scale & 68.24 & 17.87 & 66.38 & 19.58 & $* * *$ & 62.79 & 20.73 & 61.96 & 19.74 & \\
\hline CES-D-10 depression scale & 4.61 & 4.49 & 5.17 & 5.15 & $* * *$ & 5.80 & 5.31 & 6.09 & 5.38 & \\
\hline Severe illness spouse & 0.02 & 0.15 & 0.08 & 0.27 & $* * *$ & 0.02 & 0.15 & 0.06 & 0.23 & $* * *$ \\
\hline Severe illness close family & 0.11 & 0.32 & 0.18 & 0.38 & $* * *$ & 0,12 & 0,32 & 0,25 & 0,43 & $* * *$ \\
\hline \multicolumn{11}{|l|}{ Personal characteristics } \\
\hline Age & 54.05 & 5.49 & 54.54 & 5.07 & $* * *$ & 53.18 & 5.54 & 53.50 & 5.24 & \\
\hline Age Squared & 2951.4 & 594.2 & 2999.9 & 551.3 & $* * *$ & 2858.9 & 595.1 & 2890.2 & 565.9 & \\
\hline Married/registered partnership & 0.89 & 0.31 & 0.88 & 0.33 & $* * *$ & 0.82 & 0.38 & 0.79 & 0.41 & $* * *$ \\
\hline Children living at home & 0.49 & 0.50 & 0.46 & 0.50 & $* * *$ & 0.44 & 0.50 & 0.42 & 0.49 & \\
\hline \multicolumn{11}{|l|}{ Informal caregiving } \\
\hline Average care duration (\# waves) & & & 2.02 & 1.14 & $* * *$ & & & 2.42 & 1.22 & $* * *$ \\
\hline Number of observations in $T_{1}$ & 3,006 & & 1,394 & & & 1,648 & & 1,880 & & \\
\hline
\end{tabular}

SF-12 PCS and MCS and SF-36 Vitality range from 0 to 100 (lowest - highest level of health). CES-D-10 ranges from 0 to 30 , a score $\geq 10$ is considered a sign of depression. ${ }^{* * * *} \mathrm{p}<0.01 ;{ }^{* * *} \mathrm{p}<0.05 ;{ }^{*} \mathrm{p}<0.1$ indicate differences between never and ever IC sample. 
Table A5

A-B estimates for males and females.

\begin{tabular}{|c|c|c|c|c|c|c|c|c|}
\hline \multirow[t]{2}{*}{ A-B } & \multicolumn{4}{|l|}{ Males } & \multicolumn{4}{|l|}{ Females } \\
\hline & SF-12 PCS & SF-12 MCS & SF-36 vitality & CES-D-10 depression & SF-12 PCS & SF-12 MCS & SF-36 vitality & CES-D-10 depression \\
\hline Informal care & $-0.56 * *(0.27)$ & $-0.06(0.29)$ & $-0.22(0.48)$ & $-0.09(0.14)$ & $0.34(0.27)$ & $-0.81 * *(0.32)$ & $-0.79(0.49)$ & $0.34 * *(0.14)$ \\
\hline Severe illness close family & $0.11(0.19)$ & $-0.37(0.23)$ & $-0.45(0.35)$ & $0.15(0.11)$ & $0.19(0.23)$ & $-0.51 * *(0.25)$ & $-0.14(0.41)$ & $0.19(0.12)$ \\
\hline Hansen J-test & $0.67(0.71)$ & $0.18(0.91)$ & $3.50(0.18)$ & $0.84(0.66)$ & $0.18(0.91)$ & $0.97(0.62)$ & $0.93(0.63)$ & $2.71(0.26)$ \\
\hline Number of instruments & 3 & 3 & 3 & 3 & 3 & 3 & 3 & 3 \\
\hline $\mathrm{N}$ & 7,588 & 7,588 & 8,228 & 8,222 & 6,038 & 6,038 & 6,596 & 6,600 \\
\hline Unique indiv. & 4,127 & 4,127 & 4,377 & 4,375 & 3,303 & 3,303 & 3,515 & 3,518 \\
\hline
\end{tabular}

Robust standard errors are in parentheses. Included controls: lagged health, age, age ${ }^{2}$, financial difficulties, married, children at home, employed, standardized household income, mother alive, father alive, wave dummies. ${ }^{* * * *} \mathrm{p}<0.01$; ${ }^{* * *} \mathrm{p}<0.05$; $\mathrm{p}<0.1$.

Table A6

First stage statistics of A-B estimations.

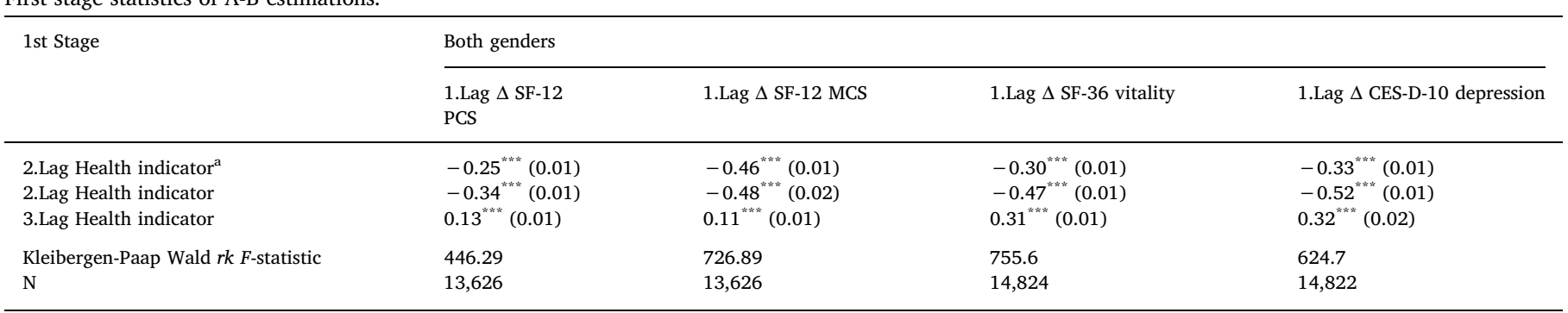

a. As the instrument matrix is not collapsed, we have separate instruments dependent on whether only the 2nd lag, or both the 2nd and 3rd lag of health can be used as instruments. Robust standard errors are in parentheses. These regressions also include: informal care, severe illness of spouse/family member, age, age ${ }^{2}$, financial difficulties, children at home, married, employed, financial difficulties, standardized household income, mother alive, father alive, wave dummies. ${ }^{* * *} \mathrm{p}<0.01$; ${ }_{* * *} \mathrm{p}<0.05 ; \mathrm{p}<0.1$. Depending on the model that is estimated, lagged health refers to the lag of the corresponding dependent variable.

Table A7

A-B estimates for higher intensity informal caregivers.

\begin{tabular}{|c|c|c|c|c|c|c|c|c|}
\hline \multirow[t]{2}{*}{ A-B Intensive care } & \multicolumn{4}{|l|}{ Males } & \multicolumn{4}{|l|}{ Females } \\
\hline & SF-12 PCS & SF-12 MCS & SF-36 vitality & CES-D-10 depression & SF-12 PCS & SF-12 MCS & SF-36 vitality & CES-D-10 depression \\
\hline $1-7 \mathrm{~h}$ of informal care & $-0.54^{*}(0.30)$ & $0.10(0.32)$ & $-0.16(0.53)$ & $-0.18(0.16)$ & $0.29(0.28)$ & $-0.69^{* * *}(0.33)$ & $-0.47(0.52)$ & $0.37^{* * *}(0.15)$ \\
\hline$\geq 8 \mathrm{~h}$ of informal care & $-0.62(0.38)$ & $-0.52(0.45)$ & $-0.39(0.71)$ & $0.17(0.23)$ & $0.54(0.42)$ & $-1.25^{\text {**kik }}(0.45)$ & $-1.95^{\text {*⿻一丿 }}(0.74)$ & $0.25(0.20)$ \\
\hline Severe illness close family & $0.11(0.19)$ & $-0.36(0.23)$ & $-0.45(0.35)$ & $0.14(0.11)$ & $0.18(0.23)$ & $-0.50^{\text {**k }}(0.25)$ & $-0.12(0.41)$ & $0.19(0.12)$ \\
\hline Hansen J-test & $0.67(0.72)$ & $0.18(0.91)$ & $3.51(0.17)$ & $0.85(0.65)$ & $0.18(0.92)$ & $0.97(0.62)$ & $0.95(0.62)$ & $2.73(0.26)$ \\
\hline Number of instruments & 3 & 3 & 3 & 3 & 3 & 3 & 3 & 3 \\
\hline $\mathrm{N}$ & 7,588 & 7,588 & 8,228 & 8,222 & 6,038 & 6,038 & 6,596 & 6,600 \\
\hline Unique indiv. & 4,127 & 4,127 & 4,377 & 4,375 & 3,303 & 3,303 & 3,515 & 3,518 \\
\hline
\end{tabular}

Robust standard errors are in parentheses. Included controls: lagged health, age, age ${ }^{2}$, financial difficulties, married, children at home, employed, standardized household income, mother alive, father alive, wave dummies. ${ }^{* * * *} \mathrm{p}<0.01 ;{ }^{* * *} \mathrm{p}<0.05 ;{ }^{*} \mathrm{p}<0.1$.

Table A8

A-B estimates informal care to various types of care receivers.

\begin{tabular}{|c|c|c|c|c|c|c|c|c|}
\hline A-B & $\begin{array}{l}\text { Males } \\
\text { SF-12 PCS }\end{array}$ & SF-12 MCS & SF-36 vitality & CES-D-10 depression & $\begin{array}{l}\text { Females } \\
\text { SF-12 PCS }\end{array}$ & SF-12 MCS & SF-36 vitality & CES-D-10 depression \\
\hline Informal care to spouse & $-1.59^{\text {*.*i }}(0.74)$ & $-0.17(0.84)$ & $0.92(1.32)$ & $0.37(0.40)$ & $0.15(1.02)$ & $-2.22^{*}(1.27)$ & $-5.47^{* * * * k}(1.56)$ & $1.20^{\text {k**k }}(0.37)$ \\
\hline Informal care to parent & $-0.66^{*}(0.34)$ & $0.15(0.39)$ & $0.17(0.62)$ & $-0.21(0.20)$ & $0.55(0.36)$ & $-0.98^{* * *}(0.43)$ & $-0.28(0.66)$ & $0.28(0.20)$ \\
\hline Informal care to other person & $-0.20(0.37)$ & $-0.21(0.40)$ & $-0.78(0.70)$ & $-0.11(0.20)$ & $0.16(0.40)$ & $-0.39(0.42)$ & $-0.56(0.68)$ & $0.26(0.18)$ \\
\hline Severe illness spouse & $-0.28(0.44)$ & $-0.77(0.55)$ & $-1.20(0.84)$ & $0.18(0.26)$ & $-0.03(0.50)$ & $-1.39^{* * *}(0.68)$ & $-1.89^{*}(0.99)$ & $0.70^{* * *}(0.28)$ \\
\hline Severe illness close family & $0.15(0.20)$ & $-0.20(0.24)$ & $-0.28(0.39)$ & $0.17(0.12)$ & $0.21(0.24)$ & $-0.25(0.25)$ & $0.26(0.43)$ & $0.06(0.12)$ \\
\hline Hansen J-test & $0.73(0.39)$ & $0.16(0.69)$ & $3.36(0.07)$ & $0.83(0.36)$ & $0.17(0.68)$ & $1.59(0.21)$ & $1.17(0.28)$ & $2.74(0.10)$ \\
\hline Number of instruments & 3 & 3 & 3 & 3 & 3 & 3 & 3 & 3 \\
\hline $\mathrm{N}$ & 7,588 & 7,588 & 8,228 & 8,222 & 6,038 & 6,038 & 6,596 & 6,600 \\
\hline Unique indiv. & 4,127 & 4,127 & 4,377 & 4,375 & 3,303 & 3,303 & 3,515 & 3,518 \\
\hline
\end{tabular}

Robust standard errors are in parentheses. Included controls: Lagged health, age, age ${ }^{2}$, financial difficulties, married, children at home, employed, financial difficulties, standardized household income, wave dummies. ${ }^{* * * *} \mathrm{p}<0.01 ;{ }^{* * *} \mathrm{p}<0.05 ;$ " $\mathrm{p}<0.1$. 
Table A9

OLS estimates of main model.

\begin{tabular}{|c|c|c|c|c|}
\hline \multirow[t]{2}{*}{ OLS } & \multicolumn{4}{|l|}{ Both genders } \\
\hline & SF-12 PCS & SF-12 MCS & SF-36 vitality & CES-D-10 depression \\
\hline Informal care & $-0.24^{* *}(0.10)$ & $-0.31^{* * * *}(0.11)$ & $-0.57^{* * * *}(0.19)$ & $0.18^{* * * x}(0.06)$ \\
\hline Severe illness spouse/family & $-0.22^{*}(0.12)$ & $-0.80^{\text {*k*k }}(0.13)$ & $-0.90^{* * * *}(0.22)$ & $0.34^{\text {****k }}(0.07)$ \\
\hline Lagged health & $0.71^{* * * *}(0.01)$ & $0.53^{* * * * *}(0.01)$ & $0.69^{* \text { *** }}(0.01)$ & $0.63^{\text {k.t.k }}(0.01)$ \\
\hline Age & $-1.38^{\text {kikkt }}(0.16)$ & $-1.01^{k * * *}(0.18)$ & $-2.55^{* * * *}(0.32)$ & $0.65^{* * * x}(0.10)$ \\
\hline Age squared/100 & $1.30^{\text {**** }}(0.15)$ & $1.01^{* * * *}(0.16)$ & $2.47^{* * * *}(0.28)$ & $-0.62^{* * * k}(0.09)$ \\
\hline Married/Registered partnership & $0.13(0.12)$ & $0.76^{\text {*k*k }}(0.15)$ & $1.21^{* * * k}(0.25)$ & $-0.47^{\text {*k*kt }}(0.08)$ \\
\hline Children living at home & $0.42^{* * * k}(0.09)$ & $0.05(0.11)$ & $0.50^{* *}(0.19)$ & $-0.08(0.06)$ \\
\hline Employed & $2.63^{\text {***k}}(0.12)$ & $1.49^{* k *}(0.15)$ & $2.77^{* * * *}(0.26)$ & $-1.05^{\text {*k.kik }}(0.08)$ \\
\hline Financial difficulties & $-0.63^{\text {**ke }}(0.12)$ & $-1.05^{* k *}(0.14)$ & $-2.34^{* \ldots * *}(0.23)$ & $0.77^{\text {*⿻*k*t }}(0.07)$ \\
\hline Perc. group household income & $0.01^{k * * *}(0.00)$ & $0.01^{* * k}(0.00)$ & $0.01^{* * * *}(0.00)$ & $-0.01^{k \ldots k \kappa}(0.00)$ \\
\hline Mother Alive & $0.17^{*}(0.09)$ & $0.08(0.10)$ & $0.24(0.17)$ & $-0.10^{*}(0.05)$ \\
\hline Father Alive & $0.29^{*}(0.09)$ & $-0.02(0.11)$ & $0.19(0.19)$ & $-0.06(0.05)$ \\
\hline $\mathrm{N}$ & 21,539 & 21,539 & 22,789 & 22,787 \\
\hline
\end{tabular}

Robust standard errors are in parentheses. All regressions include wave dummies. ${ }^{* * * *} \mathrm{p}<0.01$; ${ }^{* * *} \mathrm{p}<0.05$; $\mathrm{p}<0.1$. Depending on the model that is estimated, lagged health refers to the lag of the corresponding dependent variable.

Table A10

Fixed effects estimates of main model.

\begin{tabular}{|c|c|c|c|c|}
\hline Fixed Effects & \multicolumn{4}{|l|}{ Both genders } \\
\hline Informal care & $-0.07(0.17)$ & $-0.34^{*}(0.18)$ & $-0.47(0.30)$ & $0.15^{*}(0.08)$ \\
\hline Lagged health & $-0.25^{* * * k}(0.01)$ & $-0.26^{\text {**** }}(0.01)$ & $-0.24^{* * * *}(0.01)$ & $-0.27^{* * * k}(0.01)$ \\
\hline Age & $0.37(0.54)$ & $-0.47(0.56)$ & $-0.45(1.01)$ & $0.36(0.28)$ \\
\hline Age squared/100 & $-0.43(0.47)$ & $0.63(0.49)$ & $0.74(0.88)$ & $-0.38(0.24)$ \\
\hline Married/Registered partnership & $-0.55(0.50)$ & $1.73^{\text {kit }}(0.60)$ & $1.85^{* \ldots \times}(0.93)$ & $-1.11^{k, k * k}(0.31)$ \\
\hline Financial difficulties & $-0.26(0.18)$ & $-0.42^{* * * * *}(0.21)$ & $-1.46^{\text {***t* }}(0.35)$ & $0.43^{* . * 2 * t}(0.10)$ \\
\hline Perc. group household income & $-0.00^{*}(0.01)$ & $0.00(0.01)$ & $0.00(0.01)$ & $0.00(0.00)$ \\
\hline Mother Alive & $-0.32(0.35)$ & $-0.48(0.34)$ & $-0.49(0.60)$ & $0.09(0.18)$ \\
\hline Father Alive & $0.60(0.38)$ & $-0.12(0.45)$ & $0.32(0.72)$ & $0.07(0.20)$ \\
\hline $\mathrm{N}$ & 21,539 & 21,539 & 22,789 & 22,787 \\
\hline Unique individuals & 7,906 & 7,906 & 7,957 & 7,958 \\
\hline
\end{tabular}

Robust standard errors are in parentheses. All regressions include wave dummies. ${ }^{* * * *} \mathrm{p}<0.01$; ${ }^{* *} \mathrm{p}<0.05$; $\mathrm{p}<0.1$. Depending on the model that is estimated, lagged health refers to the lag of the corresponding dependent variable.

Table A11

Robustness check, using LTC eligibility as health shock.

\begin{tabular}{lllll}
\hline A-B & Both genders & & \\
\cline { 2 - 5 } & SF-12 PCS & SF-12 MCS & SF-36 vitality & CES-D-10 depression \\
\hline Informal care & $-0.01(0.19)$ & $-0.46^{\text {*** }}(0.22)$ & $-0.50(0.35)$ & $0.12(0.10)$ \\
LTC-eligibility & $-0.34(0.22)$ & $0.33(0.28)$ & $0.43)$ & $0.26^{\text {*** }}(0.13)$ \\
Hansen J-test & $0.5(0.78)$ & $1.09(0.58)$ & $3.80(0.25)$ & $3.08(0.22)$ \\
Number of instruments & 3 & 3 & 14,657 & 14,656 \\
N & 13,485 & 7,385 & 7,830 & 7,831 \\
Unique individuals & 7,376 & 7,376 & \\
\hline
\end{tabular}

Robust standard errors are in parentheses. Included controls: Lagged health, age, age ${ }^{2}$, financial difficulties, married, children at home, employed, financial difficulties, standardized household income and wave dummies. ${ }^{* * * *} \mathrm{p}<0.01$; ${ }^{* * *} \mathrm{p}<0.05$; $\mathrm{p}<0.1$ 
Table A12

Robustness check, including additional covariates regarding health of family members.

\begin{tabular}{|c|c|c|c|c|}
\hline \multirow[t]{2}{*}{ Post-LASSO } & \multicolumn{4}{|l|}{ Both genders } \\
\hline & SF-12 PCS & SF-12 MCS & SF-36 vitality & CES-D-10 depression \\
\hline Informal care & $-0.11(0.20)$ & $-0.39^{*}(0.22)$ & $-0.45(0.36)$ & $0.13(0.11)$ \\
\hline Lagged health & $0.09^{* * * * *}(0.03)$ & $0.12^{* * * *}(0.02)$ & $0.09^{* * * * k}(0.02)$ & $0.09^{k * * * *}(0.02)$ \\
\hline Age squared / 100 & $-0.04(0.08)$ & $-0.16^{*}(0.09)$ & $-0.33^{* * k}(0.15)$ & $0.06(0.04)$ \\
\hline Employed & $0.47(0.29)$ & $-0.29(0.32)$ & $-1.71^{* * *}(0.55)$ & $-0.01(0.16)$ \\
\hline Poor & $-0.28(0.22)$ & $-0.18(0.26)$ & $-1.08^{* * * *}(0.42)$ & $0.30^{* * *}(0.12)$ \\
\hline Perc. group household income & $-0.01(0.01)$ & $0.02^{*}(0.01)$ & $0.01(0.01)$ & $-0.00(0.00)$ \\
\hline Self-reported illness family & $0.10(0.15)$ & $-0.48^{* * * k t}(0.17)$ & $-0.46^{*}(0.28)$ & $0.18^{k * k}(0.08)$ \\
\hline Children at home & $0.03(0.31)$ & & $-0.79(0.58)$ & \\
\hline Spouse - prescription for drugs used in diabetes & $2.81^{k * k}(1.20)$ & & & \\
\hline Mother - prescription for drugs for obstructive airway diseases & $0.36(0.39)$ & & & \\
\hline Father - prescription for endocrine therapy & $0.06(0.81)$ & & & \\
\hline Married & & $0.87(0.81)$ & $0.78(1.16)$ & $-0.44(0.37)$ \\
\hline Mother - prescription for psycho-analeptics & & $-0.41(0.41)$ & $0.07(0.66)$ & $-0.25(0.19)$ \\
\hline Spouse - prescription other products for alimentary tract and metabolism & & $0.29(0.83)$ & & \\
\hline Mother - prescription for digestives. including enzymes & & $1.03(1.65)$ & & \\
\hline Father - health expenses abroad & & $0.00^{*}(0.00)$ & & \\
\hline Spouse - prescription for psycho-analeptics & & & $-1.51(0.94)$ & \\
\hline Spouse - Eligible for LTC & & & $-0.88(1.62)$ & $0.55(0.51)$ \\
\hline Mother - prescription for muscle relaxants & & & & $0.37(0.84)$ \\
\hline Father - prescription for antiseptics and disinfectants & & & & $-1.86^{* * *}(0.91)$ \\
\hline Hansen J-test & $0.23(0.89)$ & $0.47(0.79)$ & $2.64(0.10)$ & $2.71(0.26)$ \\
\hline Number of instruments & 3 & 3 & 3 & 3 \\
\hline $\mathrm{N}$ & 12,791 & 12,791 & 13,922 & 13,919 \\
\hline Unique individuals & 6,595 & 6,595 & 6,990 & 6,990 \\
\hline
\end{tabular}

Robust standard errors are in parentheses. All regressions include wave dummies. ${ }^{* * * *} \mathrm{p}<0.01$; ${ }^{* * *} \mathrm{p}<0.05 ;$; $\mathrm{p}<0.1$. Depending on the model that is estimated, lagged health refers to the lag of the corresponding dependent variable.

Table A13

Robustness check, main model using bias correction.

\begin{tabular}{|c|c|c|c|c|}
\hline \multirow[t]{2}{*}{ Bias correction ( 99 bootstraps) } & \multicolumn{4}{|l|}{ Both genders } \\
\hline & SF-12 PCS & SF-12 MCS & SF-36 vitality & CES-D-10 depression \\
\hline Informal care & $-0.14(0.18)$ & $-0.32^{*}(0.19)$ & $-0.52^{*}(0.30)$ & $0.14^{*}(0.08)$ \\
\hline Severe illness spouse/family & $0.13(0.12)$ & $-0.37^{* \ldots *}(0.13)$ & $-0.24(0.22)$ & $0.16^{\text {k** }}(0.07)$ \\
\hline Lagged health & $0.09^{* k * k}(0.01)$ & $0.06^{* * * *}(0.01)$ & $0.07^{* * * *}(0.01)$ & $0.06^{\text {****x }}(0.01)$ \\
\hline Employed & $0.39^{*}(0.21)$ & $0.09(0.23)$ & $-1.54^{\text {k*k*k }}(0.44)$ & $-0.09(0.11)$ \\
\hline Financial difficulties & $-0.22(0.20)$ & $-0.34(0.21)$ & $-1.38^{* k * k}(0.33)$ & $0.38^{\text {**** }}(0.10)$ \\
\hline Perc. group household income & $-0.01(0.01)$ & $0.00(0.01)$ & $0.00(0.01)$ & $0.00(0.00)$ \\
\hline Age & $0.63(0.49)$ & $-0.97^{*}(0.54)$ & $-0.92(0.88)$ & $0.45(0.29)$ \\
\hline Age squared / 100 & $-0.64(0.45)$ & $0.70(0.48)$ & $0.35(0.79)$ & $-0.31(0.26)$ \\
\hline Married/Registered partnership & $-0.59(0.43)$ & $1.51^{k \cdots * k}(0.46)$ & $1.68^{k * k}(0.84)$ & $-0.88^{* * \pi / k}(0.23)$ \\
\hline Children living at home & $0.14(0.26)$ & $-0.44(0.28)$ & $-0.68(0.51)$ & $0.14(0.13)$ \\
\hline Mother Alive & $-0.21(0.35)$ & $-0.69^{*}(0.38)$ & $-0.67(0.66)$ & $0.12(0.19)$ \\
\hline Father Alive & $0.69^{* * k}(0.33)$ & $-0.02(0.36)$ & $0.24(0.72)$ & $0.01(0.20)$ \\
\hline $\mathrm{N}$ & 21,539 & 21,539 & 22,789 & 22,787 \\
\hline Unique individuals & 7,906 & 7,906 & 7,957 & 7,958 \\
\hline
\end{tabular}

Standard errors are in parentheses. All regressions include wave dummies. ${ }^{* * * *} \mathrm{p}<0.01 ;{ }^{* * *} \mathrm{p}<0.05 ;{ }^{*} \mathrm{p}<0.1$. Depending on the model that is estimated, lagged health refers to the lag of the corresponding dependent variable.

\section{References}

Amirkhanyan, A.A., Wolf, D.A., 2006. Parent care and the stress process: findings from panel data. J. Gerontol. 61 (5), S248-S255. https://doi.org/10.1093/geronb/61.5. S248.

Andresen, E.M., Malmgren, J.A., Carter, W.B., Patrick, D.L., 1994. Screening for depression in well older adults: evaluation of a short form of the CES-D. Am. J. Prev. Med. 10 (2), 77-84. https://doi.org/10.1016/s0749-3797(18)30622-6.

Angrist, J.D., Pischke, J.S., 2008. Mostly Harmless Econometrics: An Empiricist's Companion. Princeton University Press, Princeton, NJ.

Arellano, M., Bond, S., 1991. Some tests of specification for panel data: Monte Carlo evidence and an application to employment equations. Rev. Econ. Stud. 58 (2), 277-297. https://doi.org/10.2307/2297968.

Belloni, A., Chen, D., Chernozhukov, V., Hansen, C., 2012. Sparse models and methods for optimal instruments with an application to eminent domain. Econometrica 80 (6), 2369-2429. https://doi.org/10.3982/ECTA9626.

Bobinac, A., Van Exel, N.J.A., Rutten, F.F.H., Brouwer, W.B.F., 2010. Caring for and caring about: disentangling the caregiver effect and the family effect. J. Health Econ. 29 (4), 549-556. https://doi.org/10.1016/j.jhealeco.2010.05.003.
Bond, S.R., 2002. Dynamic panel data models: a guide to micro data methods and practice. Port. Econ. J. 1, 141-162. https://doi.org/10.1007/s10258-002-0009-9.

Bound, J., 1991. Self-reported versus objective measures of health in retirement models. J. Human Resour. 26 (1), 106-138. https://doi.org/10.2307/145718.

Brenna, E., Di Novi, C., 2016. Is caring for older parents detrimental to women's mental health? The role of the European North-South gradient. Rev. Econ. Household 14 (4), 745-778. https://doi.org/10.1007/s11150-015-9296-7.

Bruno, G.S.F., 2005. Approximating the bias of the LSDV estimator for dynamic unbalanced panel data models. Econ. Lett. 87 (3), 361-366. https://doi.org/10.1016/j. econlet.2005.01.005.

Coe, N.B., van Houtven, C.H., 2009. Caring for mom and neglecting yourself? The health effects of caring for an elderly parent. Health Econ. 18, 991-1010. https://doi.org/ 10.1002/hec.

De Zwart, P.L., Bakx, P., van Doorslaer, E.K.A., 2017. Will you still feed me when I'm 64? The health impact of caregiving. Health Econ. 26, 127-138. https://doi.org/10. 1002/hec.3542.

Do, Y.K., Norton, E.C., Stearns, S., Van Houtven, C.H., 2015. Informal care and caregiver's health. Health Econ. 24, 224-237. https://doi.org/10.1002/hec.

Eggink, E., Ras, M., Woittiez, I., 2016. Dutch long-term care use in an ageing population. 
J. Econ. Ageing 9, 63-70. https://doi.org/10.1016/j.jeoa.2016.08.001.

Gezondheidsmonitor, 2016. Own calculations using: Health monitor adults. Public Health Services, Statistics Netherlands, and National Institute for Public Health and the Environment.

Hansen, L., 1982. Large sample properties of generalized method of moments estimators. Econometrica 50 (4), 1029-1054. https://doi.org/10.2307/1912775.

Heger, D., 2016. The mental health of children providing care to their elderly parent. Health Econ. 26, 1617-1629. https://doi.org/10.1002/hec.

Hewlett, S., Dures, E., Almeida, C., 2011. Measures of fatigue. Arthritis Care Res. 63 (S11), S263-S286. https://doi.org/10.1002/acr.20579.

Hirst, M., 2004. Health Inequalities and Informal Care: End of Project Report. Social Policy Research Unit, retrieved from: https://www.york.ac.uk/inst/spru/pubs/pdf/ healthinequalities.pdf.

Lechner, M., 2009. Long-run labour market and health effects of individual sports activities. J. Health Econ. 28 (4), 839-854. https://doi.org/10.1016/j.jhealeco.2009. 05.003.

Mot, E., 2010. The Dutch system of long-term care, CPB document 204. Retrieved from: https://www.cpb.nl/sites/default/files/publicaties/download/dutch-system-longterm-care.pdf.

Pinquart, M., Sörensen, S., 2003. Differences between caregivers and noncaregivers in psychological health and physical health: a meta-analysis. Psychol. Aging 18 (2), 250-267. https://doi.org/10.1037/0882-7974.18.2.250.

Pinquart, M., Sorensen, S., 2011. Spouses, adult children, and children-in-law as caregivers of older adults: a meta-analytic comparison. Phychol. Aging, 26, 1-14. doi: 10. $1037 / \mathrm{a} 0021863$.

Rellstab, S., Bakx, P., Garcia-Gomez, P., van Doorslaer, E., 2018. The Kids are Alright Labour Market Effects of Unexpected Parental Hospitalisations in the Netherlands. Tinbergen Institute Discussion Paper 2018-049/V. https://doi.org/10.2139/ssrn. 3180592 .

Roodman, D., 2006. How to Do xtabond2: An Introduction to "Difference" and "System"
GMM in Stata. The Stata Journal, 9, 86-136. Retrieved from: https://www.statajournal.com/article.html? article $=$ st0159.

Roy, J., Schurer, S., 2013. Getting stuck in the blues: persistence of mental health problems in Australia. Health Econ. 22 (9), 1139-1157. https://doi.org/10.1002/hec. 2967.

Schmitz, H., Westphal, M., 2015. Short- and medium-term effects of informal care provision on female caregivers' health. J. Health Econ. 42, 174-185. https://doi.org/10. 1016/j.jhealeco.2015.03.002.

Schulz, R., 1990. Theoretical perspectives on caregiving: concepts, variables, and methods. In: Biegel, B.A. (Ed.), Aging and Caregiving: Theory, Research and Policy. Sage Publications, New York, pp. 27-52.

Schulz, R., Visintainer, P., Williamson, G.M., 1990. Psychiatric and physical morbidity effects of caregiving. J. Gerontol. 45 (5), 181-191. https://doi.org/10.1093/geronj/ 45.5.p181.

Statistics Netherlands (2016). Mantelzorg. Retrieved from: https://www.cbs.nl/nl-nl/artikelen/nieuws/2016/45/een-op-zeven-mantelzorgers-vindt-zichzelf-zwaarbelast/ mantelzorg.

Van den Berg, B., Fiebig, D.G., Hall, J., 2014. Well-being losses due to care-giving. J. Health Econ. 35 (1), 123-131. https://doi.org/10.1016/j.jhealeco.2014.01.008.

Ware, J.E., Kosinski, M., Keller, S.D., 1995. SF-12: How to score the SF-12 physical and mental health summary scales (2nd. ed). Boston, Massachusetts, The Health Institute, New England Medical Center.

Ware, J.E., Snow, K.K., Kosinski, M.A., Gandek, B., 1993. SF-36 Health Survey Manual and Interpretation Guide. The Health Institute, New England Medical Center, Boston, Massachusetts.

Ybema, J.F., Geuskens, G.A., Van Den Heuvel, S.G., De Wind, A., Leijten, F.R.M., Joling, C., Bongers, P.M., 2014. Study on Transitions in Employment, Ability and Motivation (STREAM): the design of a four-year longitudinal cohort study among 15,118 persons aged 45 to 64 years. Br. J. Med. Med. Res. 4 (46), 1383-1399. https://doi.org/10. 9734/bjmmr/2014/7161. 